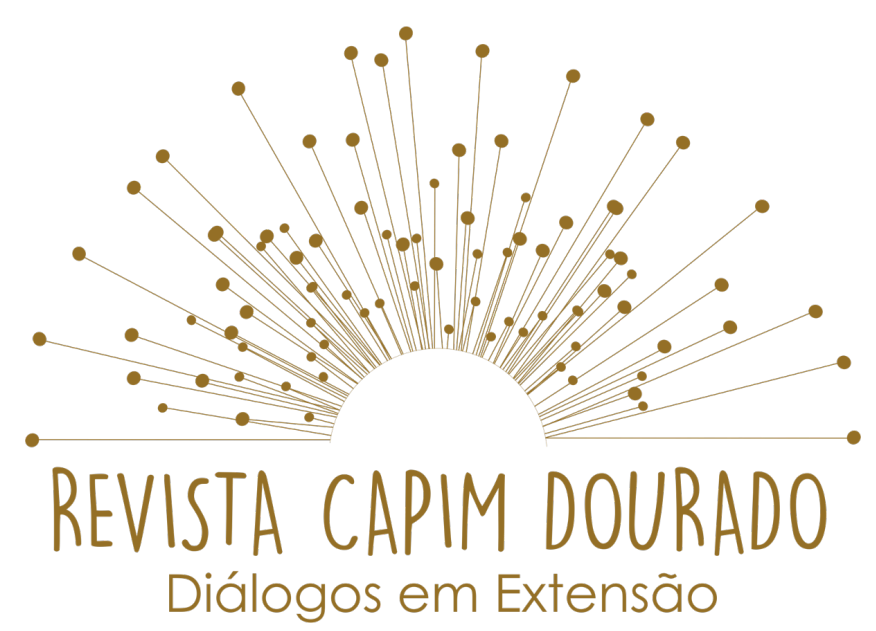

ISSN n² 2595-7341

Vol. 3, n. 1, Janeiro-Abril, 2020

DOI: http://dx.doi.org/10.20873/uft.2595-7341.2020v3n1p53

\title{
PROTAGONISMO ENTRE GERAÇÕES
}

\section{PROTAGONISM BETWEEN GENERATIONS}

PROTAGONISMO ENTRE GENERACIONES

\section{Nathália Patrício Leão ${ }^{1}$ \\ Wainesten Camargo Silva ${ }^{2}$ \\ Rodrigo de Sousa Bazzoli ${ }^{3}$ João Aparecido Bazzoli 4}

\section{RESUMO}

Em ação de extensão os jovens do Centro de Ensino Médio Santa Rita de Cássia propuseram atividade de revitalização do Centro Comunitário Viver com Alegria. Essa ação intergeracional que objetivou promover a melhoria da qualidade de vida de idosos no bairro do Jardim Aureny I/Palmas/Tocantins ao ser concluída provocou efetiva transformação social na comunidade. Foi realizada a revitalização de equipamento público essencial para os idosos, em razão da utilização deste espaço para os seus encontros semanais de dança regional/Forró, uma importante atividade de lazer e cultura. Para além disso, essa ação produziu um efeito simbólico no sentimento de pertencimento local. Sem embargo, o resultado transcendeu a revitalização física predial e urbanística. Tentou-se com a ação, fomentar a dignidade da pessoa humana, o

\footnotetext{
${ }^{1}$ Universidade Federal do Tocantins (UFT) - Direito. nathaliap@mail.uft.edu.br.

2 Universidade Federal do Tocantins (UFT) - PPGDR. wainestencamargo@gmail.com.

3 Universidade Federal do Tocantins (UFT)-PPGGEO. rodbazo@gmail.com.

4 Doutor. Professor da Universidade Federal do Tocantins (UFT)- Coordenador. jbazzoli@uft.edu.br.
} 


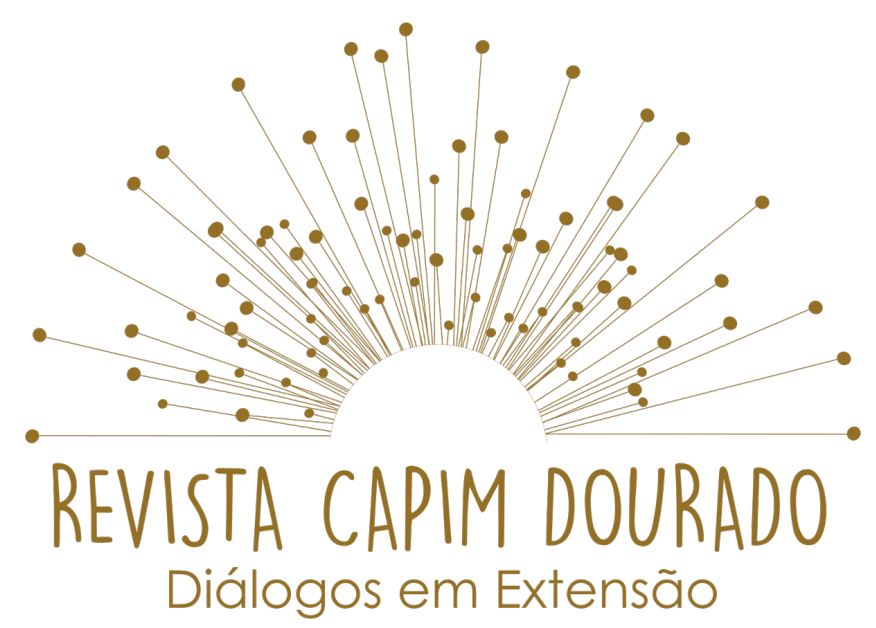

ISSN n² 2595-7341

Vol. 3, n. 1, Janeiro-Abril, 2020

DOI: http://dx.doi.org/10.20873/uft.2595-7341.2020v3n1p53

desenvolvimento humano e a garantia dos direitos fundamentais; especialmente por propiciar um espaço de lazer e cultura em bairro periférico, com elevado índice de violência. Para realizar a ação de revitalização foi utilizada a metodologia de tecnologia social, a saber: audiência pública para identificar as demandas e as prioridades da comunidade, devido ao recurso finito; mutirão de serviços de pintura e reformas; parcerias para mão de obra e realização da festa marcando a reinauguração do espaço. Registrou-se, que a demanda comunitária foi atendida integralmente a partir da ação conjugada: escola e comunidade, com apoio do voluntariado e a disponibilização de recursos da iniciativa privada, demonstrando de maneira cabal, que por meio desta tecnologia social foi possível resolver a demanda local, transformando o Nós Propomos em Nós fazemos.

PALAVRAS-CHAVE: Gerações. Nós propomos. Comunidade. Protagonismo.

\section{ABSTRACT}

In an extension action, young people from the Santa Rita de Cássia High School Center proposed revitalizing the Community Center Living with Joy. This intergenerational action aimed at improving the quality of life of the elderly in the Jardim Aureny I / Palmas / Tocantins neighborhood when completed, brought about effective social transformation in the community. The revitalization of essential public equipment for the elderly was carried out, due to the use of this space for their weekly meetings of regional dance / Forró, an important leisure and cultural activity. In addition, this action had a symbolic effect on the feeling of local belonging. However, the result went beyond the physical revitalization of buildings and urban planning. Action was taken to promote the dignity of the human person, human development and the guarantee of fundamental rights; especially for providing a space for leisure and culture in a peripheral neighborhood, with a high rate of violence. To carry out the revitalization action, the social technology methodology was used, namely: public audience to identify 


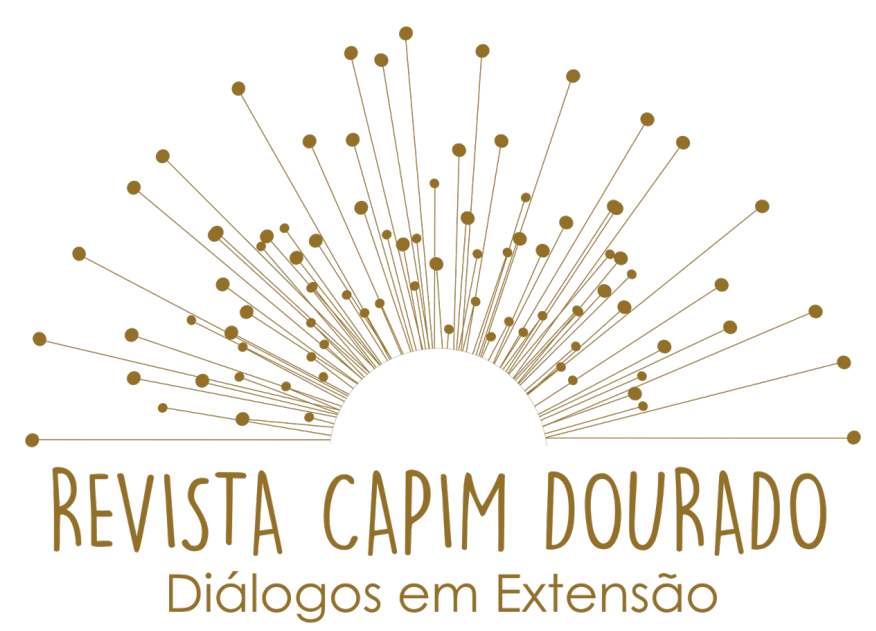

ISSN n² 2595-7341

Vol. 3, n. 1, Janeiro-Abril, 2020

DOI: http://dx.doi.org/10.20873/uft.2595-7341.2020v3n1p53

the demands and priorities of the community, due to the finite resource; task force for painting and renovation services; partnerships for labor and holding the party marking the reopening of the space. It was registered that the community demand was fully met through the joint action: school and community, with the support of volunteering and the availability of resources from the private sector, demonstrating in a complete way that through this social technology it was possible to solve the demand transforming the We Propose into We Do.

KEYWORDS: Generations. We propose. Community. Protagonism.

\section{RESUMEN}

En una acción de extensión, los jóvenes del Centro de Preparatoria Santa Rita de Cássia propusieron revitalizar el Centro Comunitario Viviendo con Alegría. Esta acción intergeneracional dirigida a mejorar la calidad de vida de las personas mayores en el barrio Jardim Aureny I / Palmas / Tocantins, una vez completada, provocó una transformación social efectiva en la comunidad. Se llevó a cabo la dinamización de equipamientos públicos imprescindibles para las personas mayores, debido a la utilización de este espacio para sus encuentros semanales de Danza Regional / Forró, importante actividad lúdica y cultural. Además, esta acción tuvo un efecto simbólico en el sentimiento de pertenencia local. Sin embargo, el resultado fue más allá de la revitalización física de los edificios y la planificación urbana. Se tomaron acciones para promover la dignidad de la persona humana, el desarrollo humano y la garantía de los derechos fundamentales; especialmente por brindar un espacio de esparcimiento y cultura en un barrio periférico, con un alto índice de violencia. Para llevar a cabo la acción de revitalización se utilizó la metodología de tecnología social, a saber: audiencia pública para identificar las demandas y prioridades de la comunidad, debido al recurso finito; grupo de trabajo para servicios de pintura y renovación; alianzas laborales y celebración de la fiesta que marca la reapertura del espacio. Se registró que la demanda comunitaria se atendió en su totalidad a través de la 


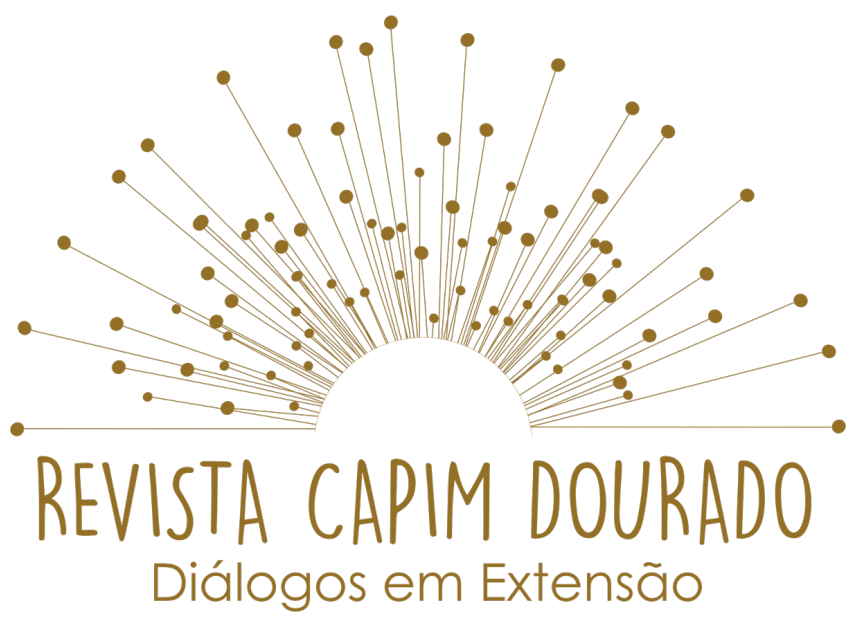

ISSN n² 2595-7341

Vol. 3, n. 1, Janeiro-Abril, 2020

DOI: http://dx.doi.org/10.20873/uft.2595-7341.2020v3n1p53

acción conjunta: escuela y comunidad, con el apoyo del voluntariado y la disponibilidad de recursos de la iniciativa privada, demostrando de manera exhaustiva que a través de esta tecnología social se pudo solucionar la demanda. transformando el We Propose en We Do.

PALABRAS CLAVE: Generaciones. Nos proponemos. Comunidad. Protagonismo.

Recebido em: 01.10.2019. Aceito em: 09.10.2019. Publicado em: 01.01.2020. 


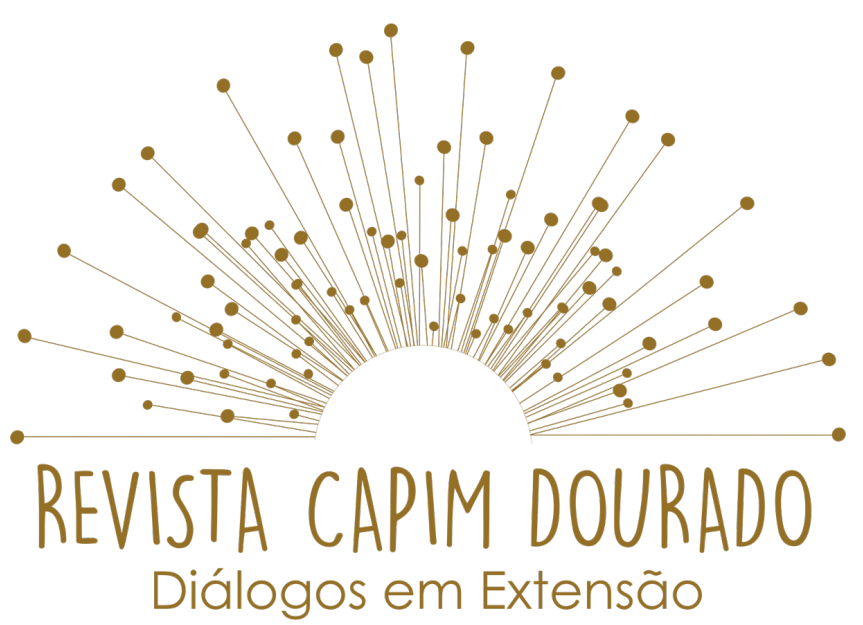

ISSN n² 2595-7341

Vol. 3, n. 1, Janeiro-Abril, 2020

DOI: http://dx.doi.org/10.20873/uft.2595-7341.2020v3n1p53

\section{INTRODUÇÃO}

Este estudo objetivou analisar a ação intergeracional de extensão universitária denominada "protagonismo entre gerações", promovida por jovens estudantes do ensino médio da rede estadual do Centro de Ensino Médio Santa Rita de Cássia.

Essa a ação fez parte do projeto Nós Propomos atrelado ao programa Cidade e Meio Ambiente: estudo ampliado em perspectiva interdisciplinar e enfocou a melhoria da qualidade de vida de idosos do bairro Jardim Aureny I e buscou promover uma efetiva transformação social nesta comunidade local. Justificou-se a ação pelo entendimento de que a reforma proposta e realizada no prédio e espaço ocupado pelo Centro Comunitário Viver com Alegria seria essencial para a elevação da autoestima dos idosos, que promovem neste local encontros semanais de dança regional/Forró.

O projeto Nós Propomos, base desta ação, desenvolvido pela Universidade Federal do Tocantins (UFT), desde 2015, por uma equipe interdisciplinar composta por alunos e professores dos cursos: Direito, Arquitetura e Urbanismo, Geografia e do Programa de Pós-Graduação em Desenvolvimento Regional, é um projeto extensionista acadêmico, que tem a finalidade de estimular os estudantes secundaristas a identificar problemas locais e "elaborar propostas de soluções para estes problemas", também, conceitualmente, passa pela necessidade da articulação social local e se faz mister "socializá-las em seminário e nas instâncias comunitárias" (BAZOLLI, 2017, p. 48). 


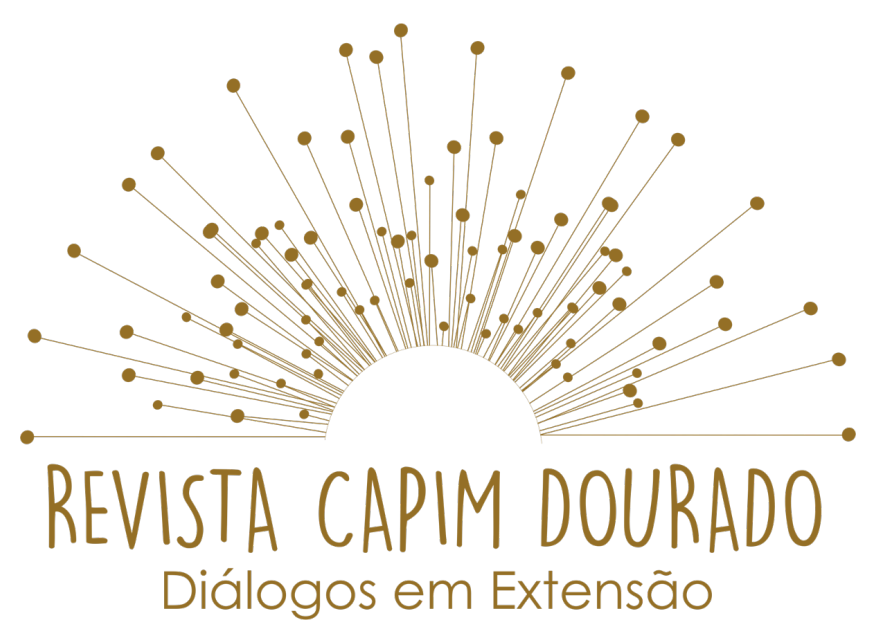

ISSN n² 2595-7341

Vol. 3, n. 1, Janeiro-Abril, 2020

DOI: http://dx.doi.org/10.20873/uft.2595-7341.2020v3n1p53

Reitera-se que a ação foi significativa pela importância para a comunidade local, no sentido de possibilitar a criação de um espaço revitalizado para prática de lazer e cultura regional. Por fim, entendia-se especialmente que o esforço resultado desta reforma produziria, como realmente produziu, um efeito simbólico no sentimento de pertencimento na população do bairro.

Buscou-se, no desenvolvimento desta ação fomentar a dignidade da pessoa humana, o desenvolvimento humano e a garantia dos direitos fundamentais; especialmente pela reforma propiciar um espaço para prática de esportes, atividades de lazer e cultura, em bairro com pouca infraestrutura urbana e com elevado índice de criminalidade.

A ação teve um enfoque metodológico na tecnologia social, partiu da identificação do problema e seguiu de um conjunto de medidas participativas na construção de um efetivo trabalho comunitário que permitiu atingir os objetivos propostos.

A ação foi desenvolvida em razão de se apresentar como proposta vencedora em 2017 no Seminário anual de avaliação onde foram apresentados 9 projetos e participaram diretamente 45 (quarenta e cinco) alunos, com repercussão interna nas escolas participantes que atingiram indiretamente, considerando o envolvimento destes nas atividades gerais promovidas pelo projeto, de mais de 500 (quinhentos) alunos.

\section{METODOLOGIA}




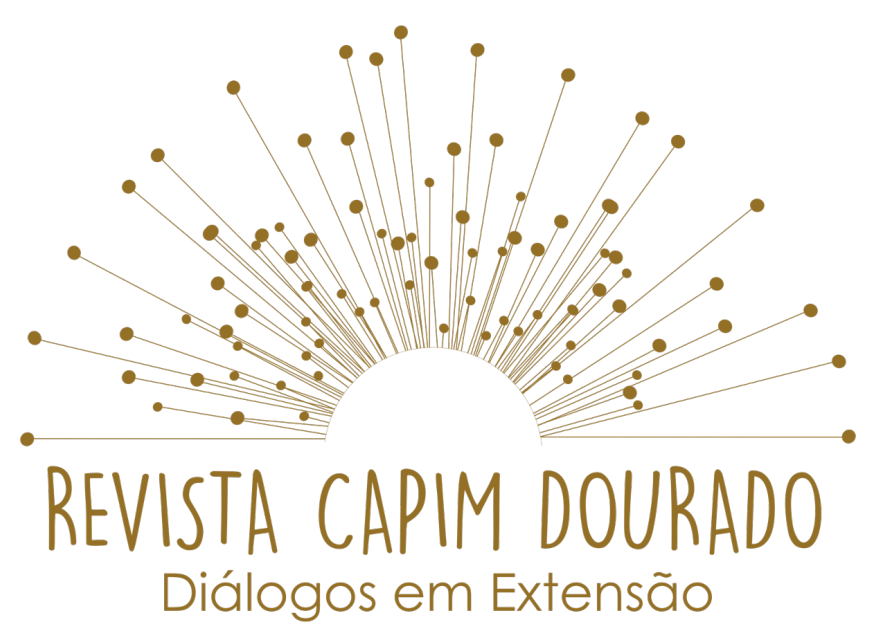

ISSN n² 2595-7341

Vol. 3, n. 1, Janeiro-Abril, 2020

DOI: http://dx.doi.org/10.20873/uft.2595-7341.2020v3n1p53

A ação intergeracional de extensão universitária denominada "protagonismo entre gerações" foi desenvolvida entre os meses de fevereiro e outubro de 2018. A metodologia utilizada de tecnologia social partiu de encontros comunitários participativos em todas as etapas de construção: identificação do problema; discussão de prioridades; realização da reforma e projeção do uso futuro. Para a reforma foi elaborado um projeto de arquitetura participativo e adotou-se para a execução dos serviços o método de mutirão comunitário, para a realização de pintura e reformas necessárias no prédio. Este trabalho foi executado com apoio do voluntariado (professores, alunos, idosos e comunidade em geral) e uso de recursos financeiros disponibilizado pela iniciativa privada, por meio de parceria com a Fundação Alphaville. Para registro dos trabalhos foi produzido um documentário (UFT, 2018) que mostra todas as etapas do desenvolvimento da ação, para além disso, o documentário mostra as entrevistas realizadas para a percepção cidadã dos atores envolvidos no trabalho de construção e os resultados efetivos da ação.

\section{FUNDAMENTAÇÃO TEÓRICA}

Para destacar o contexto da ação intergeracional de extensão universitária denominada "protagonismo entre gerações" será preciso discutir nosso objeto de estudo o projeto - Nós propomos. Este projeto de origem portuguesa foi implantado em 2011 pelo Instituto de Geografia e Ordenamento do Território da Universidade de Lisboa (IGOT-UL), expandiu-se para a Espanha, Colômbia, Peru, Moçambique, México e Brasil, "por representar um instrumento 


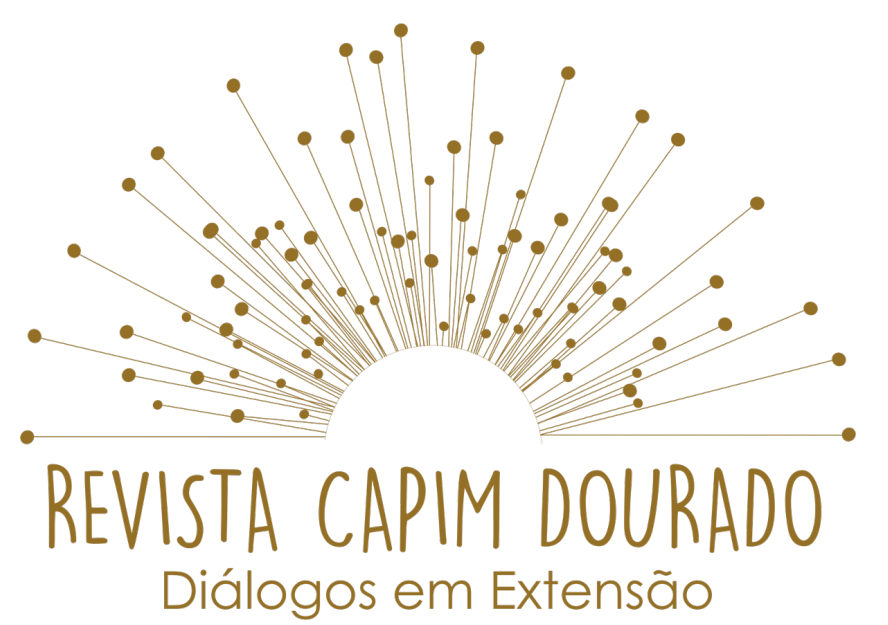

ISSN n² 2595-7341

Vol. 3, n. 1, Janeiro-Abril, 2020

DOI: http://dx.doi.org/10.20873/uft.2595-7341.2020v3n1p53

que busca despertar a cidadania ativa com enfoque na gestão democrática das cidades". (BAZOLLI, 2017, pp. 5-6).

O Projeto veio para o Tocantins em 2015 e foi implantado pela Universidade Federal em 2016, "para ser desenvolvido nas escolas de ensino médio das cidades de Palmas e Araguaína, por meio da parceria firmada com a Secretaria de Educação, Juventude e Esportes do Estado". (BAZOLLI, 2017, pp. 1327).

Detecta-se desde a sua implantação a relevância do Nós propomos como instrumento de articulação da participação popular. Os estudantes tem estreitado os laços comunitários, tomam conhecimento dos problemas sociais, culturais e da realidade econômica de sua região. Desta maneira, passam a se inserir e reconstruir a consciência de "pertencimento", ou seja, sentem-se parte desse processo de mudança e começam a verificar que podem, por meio da educação e do trabalho coletivo, encontrar possíveis resoluções para a melhoria da qualidade dos serviços públicos locais.

Ressalta-se a importância de o estudante atuando como pesquisador, no estabelecimento destes laços comunitários, esteja desprovido de preconceitos para reconhecer o protagonismo dos sujeitos locais, independentemente de níveis de escolaridade. Assim sendo, torna-se primordial se orientar pelo respeito a diversidade. Cada sujeito será dono de uma história de vida, mesmo que pareça anônima ao olhar do volume de informações produzidos na modernidade, porém, em regra geral ela terá profundidade maior que se poderia imaginar. 


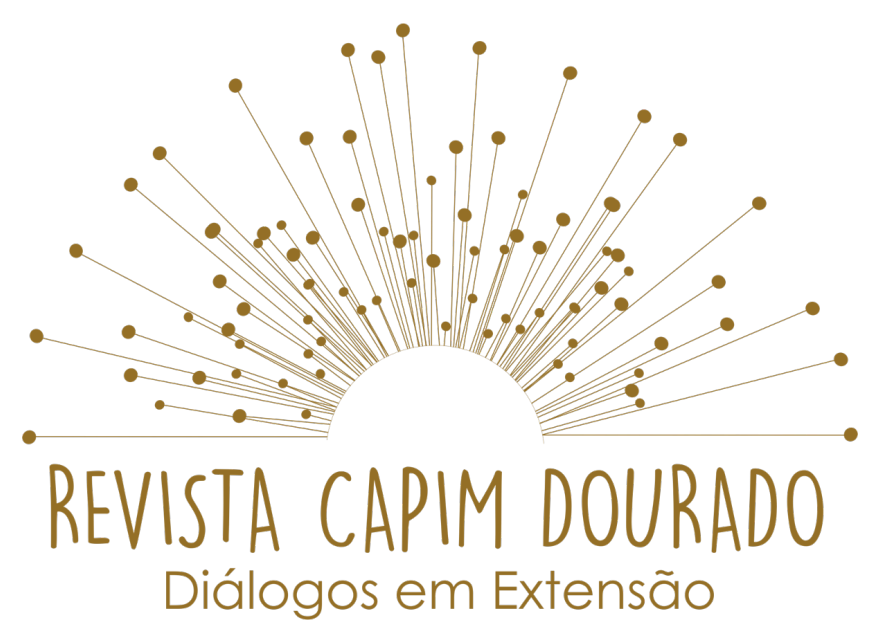

ISSN n² 2595-7341

Vol. 3, n. 1, Janeiro-Abril, 2020

DOI: http://dx.doi.org/10.20873/uft.2595-7341.2020v3n1p53

Este importante contato com a população local permite a elaboração de diagnósticos e o mapeamento dos pontos nevrálgicos e primordiais da comunidade a serem trabalhados e estudados nas rodas de palestras, reuniões de trabalho e seminários, que são realizados nas próprias escolas ou na universidade e/ou pela coordenação e equipe técnica do projeto.

Identificou-se como ponto forte do Projeto nas três edições o ativismo criativo dos estudantes, ao apontar resoluções viáveis e inovadoras para os problemas apontados nas comunidades, ouvindo a população interessada.

Assim, a extensão universitária tem o papel fundamental nesse processo dialógico entre as instituições do Estado e os atores sociais, por meio da conexão entre conhecimento científico, técnico e popular, de impor respeito e atenção às contribuições de culturas diferentes, como forma de exaltar o "exercício da ecologia de saberes" (SANTOS, 2006, p. 164), bem como recriar espaços que façam reverberar a "pedagogia da autonomia." (FREIRE, 2018, p. 39).

Nota-se que a partir dos desafios identificados para o século XXI a educação terá a necessidade de se reinventar pensando no homem do futuro, modificar o processo de ensino-aprendizagem e ter enfoque no ensino da condição humana, movida pela razão, afetividade e a emoção (MORIN, 2001, pp. 47-61). E, neste sentido a Universidade tem de assumir o seu papel de reinvenção e de modificação desejada pela sociedade.

Porquanto, o esforço engendrado no desenvolvimento do Nós Propomos pode ser considerado um caminho para a auto-formação do jovem que perpassa pelo aprendizado criativo, ou seja, compreender a arte de ensinar 


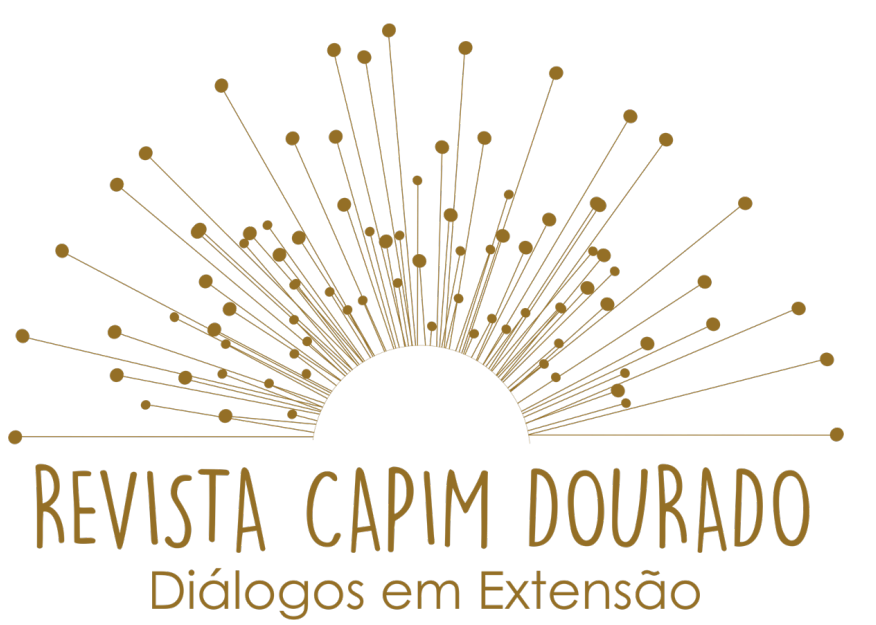

ISSN n² 2595-7341

Vol. 3, n. 1, Janeiro-Abril, 2020

DOI: http://dx.doi.org/10.20873/uft.2595-7341.2020v3n1p53

e assumir a condição humana nas suas três dimensões: labor, trabalho e ação. (ARENDT, 2007, p.15).

Nessa linha de construção epistemológica, a extensão universitária torna-se um campo fecundo e "espaço do compartilhamento da ecologia de saberes", que corresponde a um canal facilitador para a constituição de sujeitos individuais e coletivos que combinam a maior sobriedade na análise dos fatos com a intensificação da vontade da luta contra a opressão. (SANTOS, 2006, p. 164).

Neste sentido o projeto "Nós propomos" tenta "ressignificar a cidade" a partir de mudanças de paradigmas fincados "no protagonismo popular, tendo em vista a força participativa e a igualdade social" (BAZOLLI, 2017, p. 50).

\section{RESULTADOS FINAIS}

A ação intergeracional de extensão universitária denominada "protagonismo entre gerações" sustentada no Projeto Nós Propomos possibilitou, com o presente estudo, afirmar que os espaços urbanos planejados de forma coletiva, consciente e racional supõem "uma resposta pronta e adequada às demandas dos agentes, de modo a permitir que o encontro entre a ação pretendida e o objeto disponível se dê com o máximo de eficácia". (SANTOS, 2006, p. 204).

Ficou demonstrado que o grupo dos jovens estudantes do ensino médio, ao trabalhar com a realidade comunitária, foram se entusiasmando e resgatando o espírito proativo de pertencimento e a responsabilidade pelos problemas da 


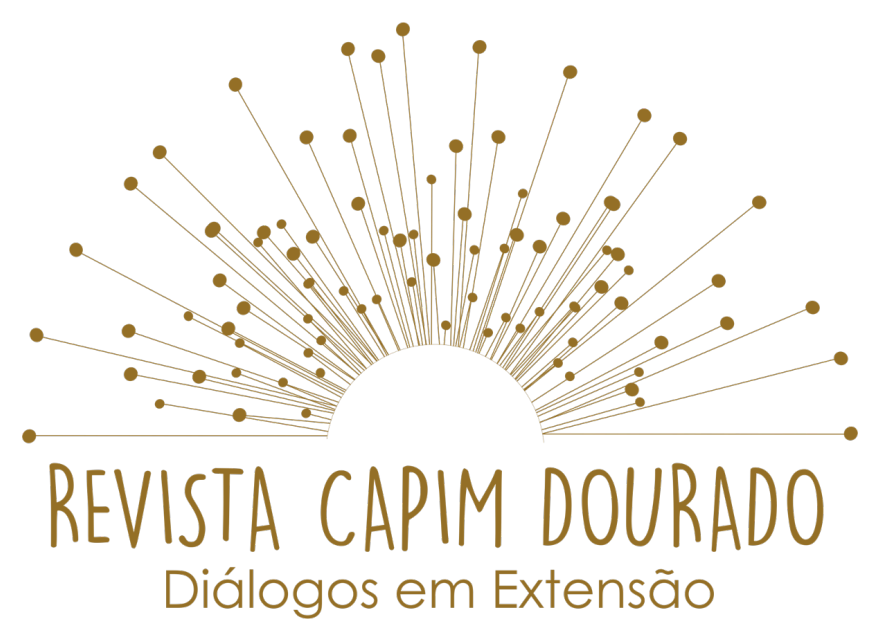

ISSN n² 2595-7341

Vol. 3, n. 1, Janeiro-Abril, 2020

DOI: http://dx.doi.org/10.20873/uft.2595-7341.2020v3n1p53

sua cidade, ratificando a "importância da extensão universitária como veículo indutor da cidadania" (BAZOLLI, 2017, p. 13-27), possibilitando ao professores entender que "ensinar não é transferir conhecimento, mas criar as possibilidades para a sua própria produção ou a sua construção". (FREIRE, 2018, p. 47).

Portanto, verificou-se que para legitimar o projeto de extensão é necessário identificar as necessidades para ter a possibilidade de orientar ações positivas e se descobriu nas audiência pública realizada com a participação ativa da comunidade que a prioridade era uma cobertura para resolver o problema de dançar em época de chuva, mostrado na Figura 1.

Figura 1: Audiência pública para identificar as necessidades da comunidade

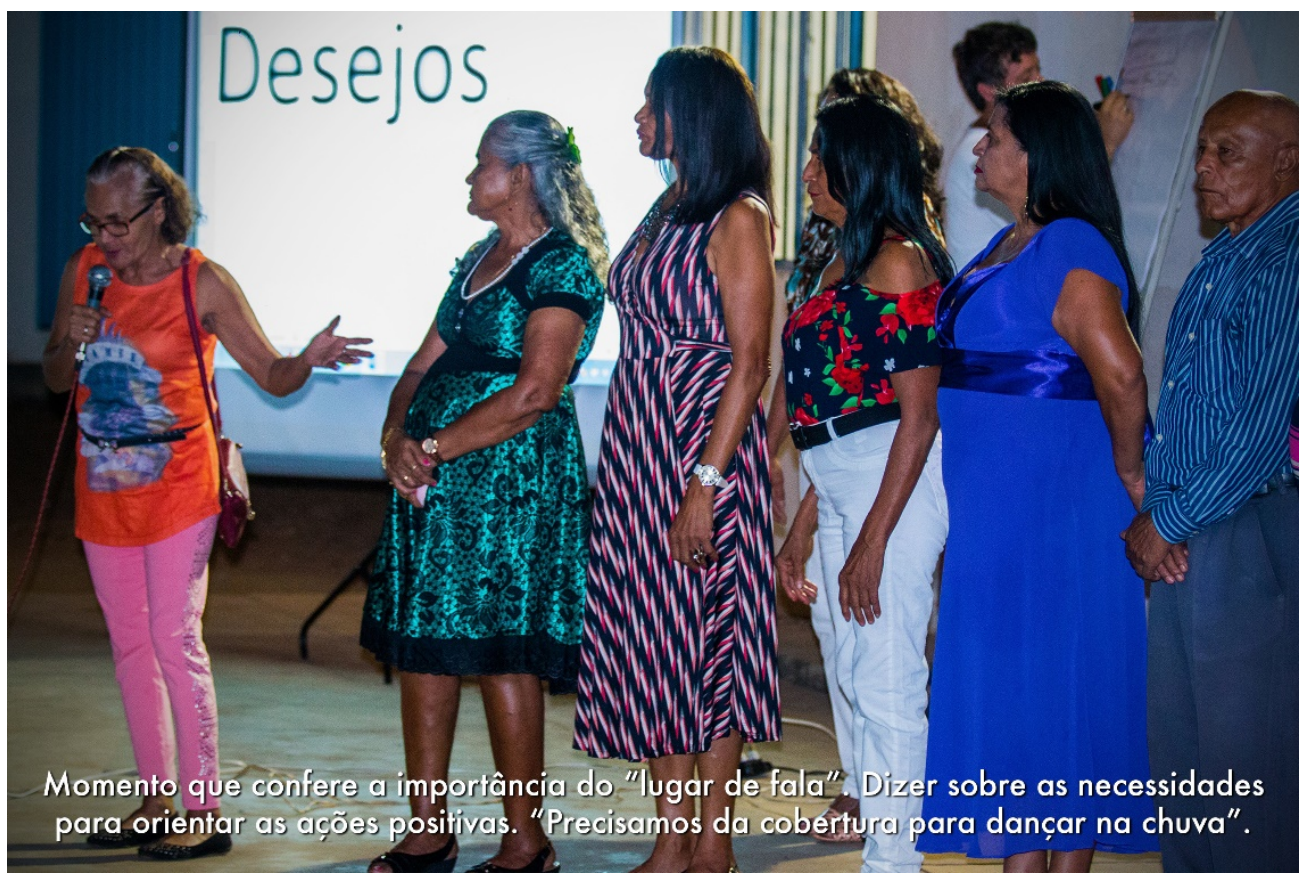

Fonte: (ALPHAVILLE, 2018, p. 15) 


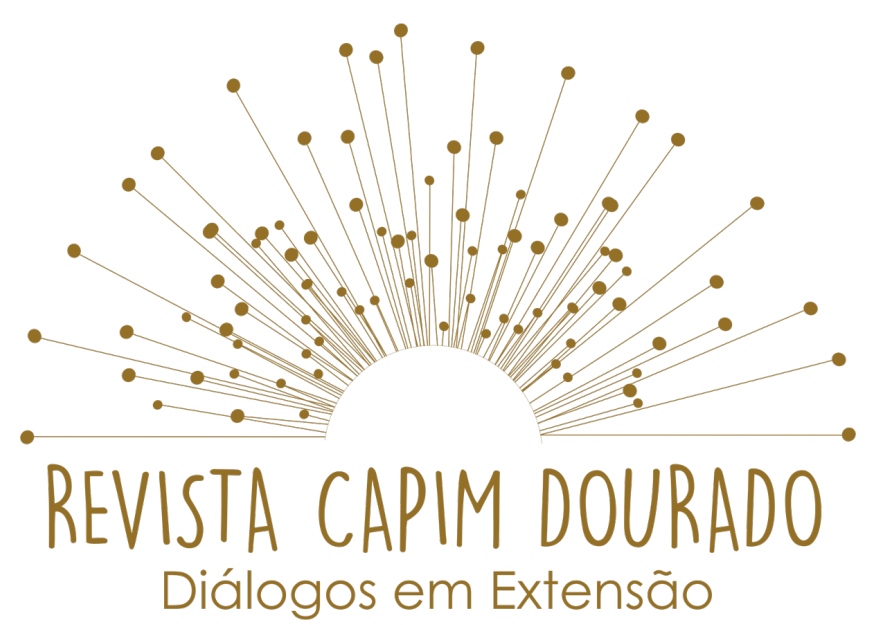

ISSN n² 2595-7341

Vol. 3, n. 1, Janeiro-Abril, 2020

DOI: http://dx.doi.org/10.20873/uft.2595-7341.2020v3n1p53

O trabalho apontou que a luta por espaços dignos à vida em comunidade não pode ser concretizada sem a escuta e colaboração da população, amplamente demonstrado. Foram beneficiados diretamente pela ação 300 famílias de inscritos no Instituto beneficiado e aproximadamente 40 jovens que estão desenvolvendo projetos no local reformado.

\section{CONSIDERAÇÕES FINAIS}

Verifica-se que ação atingiu integralmente o seu objetivo de melhorar a qualidade de vida dos idosos do bairro e de promover uma efetiva transformação social na comunidade local. A ação foi antecedida de diagnóstico do problema e de proposta de resolução apresentadas pelos jovens estudantes do (CEM Santa Rita de Cássia), instrumentalizados na intenção de concretizar efetivamente o desejo de fazer acontecer.

Pontua-se que "aos sábados, cerca de 800 pessoas se reúnem no local para "dançar". No local são atendidos os idosos, mas também "os filhos, netos, amigos dos netos". Frisa-se que "além da dança, há momentos de debate sobre assuntos diversos" e neste sentido é possível afirmar que "o impacto na qualidade de vida dos idosos é imenso" pois, "além dos benefícios para a saúde, qualidade de vida e socialização, muitos dos participantes se conhecem no forro realizado aos sábados e iniciam relacionamentos", e em decorrência destes relacionamentos acontecem casamentos. Tem-se o registro de "18 casamentos realizados entre pessoas que achavam que não tinham mais capacidade de amar". (ALPHAVILLE, 2018). 


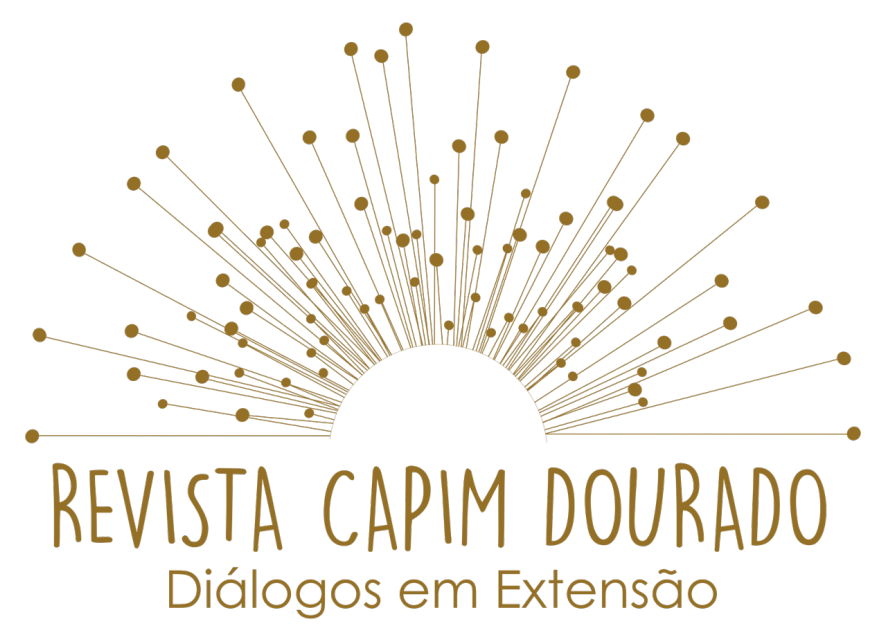

ISSN n² 2595-7341

Vol. 3, n. 1, Janeiro-Abril, 2020

DOI: http://dx.doi.org/10.20873/uft.2595-7341.2020v3n1p53

\section{REFERÊNCIAS}

ARENDT, Hannah. A condição humana. Tradução de Roberto Raposo. 10. ed. Rio de Janeiro: Forense Universitária, 2007.

BAZZOLI, J.A., et al. A extensão universitária como indutora à cidadania: a experiência do "Nós propomos". Palmas: EDUFT, 2017.

BAZZOLI, J.A. et al. Extensão e participação social: Nós Propomos! In: Geografia, educação e cidadania. (org.) Sergio Claudino et al. Lisboa: ZOE/IGOT, 2019. pp. 215-230

FREIRE, Paulo. Pedagogia da autonomia: saberes necessários à prática educativa. $56^{\mathrm{a}}$ ed. São Paulo: Paz e Terra, 2018.

ALPHAVILLE, Fundação. Protagonismo para territórios resilientes. Relatório social 2018. Disponível em: <http://fundacaoalphaville.org.br/Projeto/ViewProjeto/46> acesso em 06 out 2018.

MORIN, Edgar. Os sete saberes necessários à educação do futuro. Tradução Catarina Eleonora F. da Silva \& Jeanne Sawaya. 4. ed. São Paulo: Cortez, Brasília, DF:UNESCO, 2001.

SANTOS, Milton. A natureza do espaço: técnica e tempo, razão e emoção. 4. ed. São Paulo: Editora da Universidade de São Paulo, 2006.

UFT. Documentário. Protagonismos entre geração. Produção: Aline Ferreira Caldeira de Oliveira; fotógrafo: Gilberto Cezar; câmera - áudio e edição: Jonathan dos Santos. Palmas: Fundação Alphaville, 2018. Disponível em: $<$ https://www.youtube.com/watch?v=dPhmwciRBAc\&feature=youtu.be $>$ acesso 06 out 2018. 